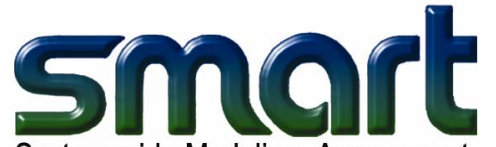

System-wide Modeling, Assessment, and Restoration Technologies

\section{Use of the Hydrological Simulation Program - FORTRAN (HSPF) Model for Watershed Studies}

by Brian E. Skahill

PURPOSE: The objectives of this document are to provide a general description of the Hydrological Simulation Program-FORTRAN (HSPF) model, its capabilities and limitations, data requirements, traditional and innovative methods for HSPF hydrologic model calibration, and to present a case study HSPF model application whereby the capabilities of HSPF and its ancillary public domain, off-the-shelf software are demonstrated as a means to support systemwide modeling and assessment in a usable decision-support framework.

BACKGROUND: The System-wide Modeling, Assessment, Restoration and Technologies (SMART) Research Program at the U.S. Army Engineer Research and Development Center (ERDC) identified several needs to support future U.S. Army Corps of Engineers (Corps) operating capabilities under the framework of environmental sustainability. These include, among others, capabilities and/or technologies to quantitatively predict future environmental conditions, as affected by the Corps and others, over a variety of spatial and temporal scales, in a decision-support framework that allows efficient assessments of ongoing and planned projects (U.S. Army Engineer Research and Development Center 2002).

The Hydrological Simulation ProgramFORTRAN (HSPF) model, a U.S. Environmental Protection Agency (EPA) sponsored, public domain, off-the-shelf, watershed scale hydrologic and water quality simulator, is one tool with a proven track record of supporting system-wide modeling and assessment. ERDC-Vicksburg has utilized the HSPF model to support water quantity and quality planning and management, point and nonpoint source pollution analyses, soil erosion and sediment transport studies, and time-series data

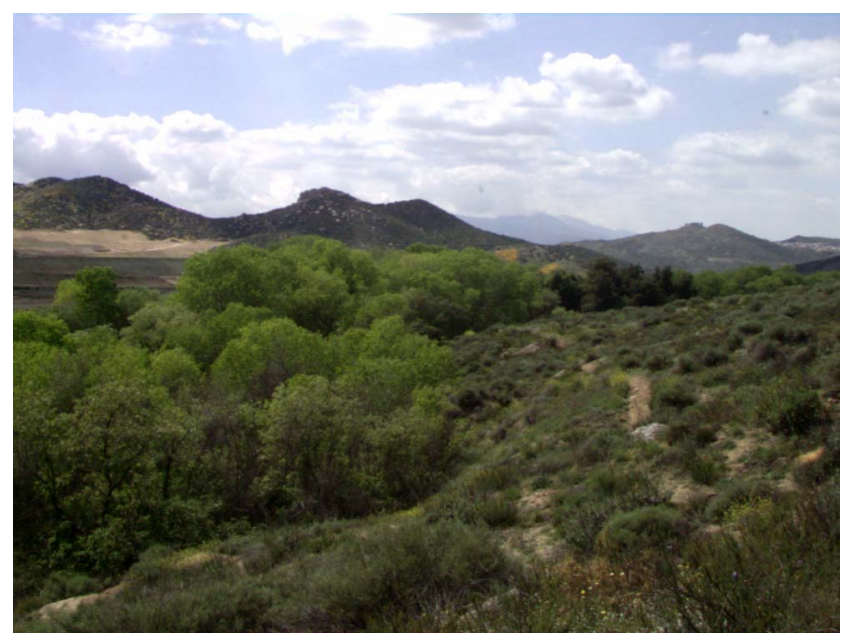
storage, analysis, and display (Deliman et al. 2001; Skahill 2002; Johnson et al. 2002). In addition, ERDC-Vicksburg has developed, and continues to support, an interface to the HSPF model in the Watershed Modeling System (WMS) (Deliman et al. 1999). WMS is a graphically based, comprehensive hydrologic modeling environment that has been developed jointly by ERDC-Vicksburg and Brigham Young University to address the needs of hydrologic and water quality computer simulations. More recent HSPF model related research and development activities conducted at ERDC-Vicksburg include supplementary hydrologic and water quality studies in support of system-wide ecosystem restoration (Smith et al. 2002), linking HSPF with 
the hydrodynamic water quality model, CE-QUAL-W2, and linkage of HSPF with parameter estimation and model uncertainty analysis procedures (Skahill et al. 2002; Skahill 2003).

\section{MODEL DESCRIPTION}

Overview. HSPF is a robust, highly complex mathematically based computer code developed under U.S. Environmental Protection Agency (EPA) sponsorship to simulate water quantity and quality processes on a continuous basis in natural and man-made water systems. HSPF uses input meteorological forcing data and parameters that are related to system geometry, land use patterns, soil characteristics, and land use activities (e.g., agricultural practices) to simulate the water quantity and quality processes that occur within a catchment. HSPF can simulate at temporal scales ranging from minutes to days. Due to its flexible modular design, HSPF can model systems of varying size and complexity; for example, "from a parking lot to a three acre farm to the Chesapeake Bay" (Munson 1998). Depending upon available resources, an HSPF modeler has access to a number of different simulation algorithms at different levels of detail and sophistication. For example, with HSPF, one could model nutrient processes in a watershed using straightforward relationships based on water and/or sediment yield or by explicitly modeling the various nutrient transformations and associated transport. The simulation algorithms available within HSPF are a mixture of physically-based and empirical approaches. The HSPF model is generally classified as a lumped parameter model; however, the spatial variability in a watershed can be simulated if the watershed is appropriately subdivided into land segments that are perceived to exhibit a homogeneous hydrologic and water quality response. Donigian et al. (1997) noted that HSPF "is the only available model that can simulate the continuous, dynamic event, or steady-state behavior of both hydrologic/hydraulic and water quality processes in a watershed, with an integrated linkage of surface, soil, and stream processes."

History. The HSPF model resulted from an EPA-funded comprehensive watershed model development effort that was conducted in the late 1970's. The effort involved integrating the field-scale EPA Agricultural Runoff Management model (ARM) (Donigian and Davis 1978) and the EPA Nonpoint Source Runoff model (NPS) (Donigian and Crawford 1979) models with the Hydrocomp Simulation Program (HSP), including HSP Quality (Hydrocomp 1977). HSP was a descendant of the Stanford Watershed model (Crawford and Linsley (1966). HSPF was first released publicly in 1980, as Release No. 5 (Johanson et al. 1980). Currently, version 12 of HSPF is available as public domain software that can be downloaded from EPA and U.S. Geological Survey (USGS) Web sites. Donigian et al. (1995) and U.S. Army Corps of Engineers (USACE) and U.S. Environmental Protection Agency (USEPA) (2000) provide graphical and tabular summaries that describe the historical progression of HSPF releases and related development activities. User support, code maintenance, and further refinement and enhancement of the HSPF model are ongoing. Since its original development, the HSPF model has been applied in various climatic regions around the world. It has been applied throughout North America. Donigian et al. (1995) discuss numerous planned and possible future development directions for the HSPF model. These directions include planned enhancements to the nitrogen transformations code section of HSPF to improve plant uptake for agricultural crops and nitrogen cycling in forested watersheds, as well as future research opportunities including habitat suitability, ecological modeling, integration of Geographic Information Systems (GIS) 
and remote sensing data, parameter estimation guidance, sensitivity analysis, and uncertainty analysis.

General Description. For an HSPF model, the watershed is subdivided into individual land segments that are assumed to produce a homogeneous hydrologic and water quality response. The purpose of the land segmentation within the watershed is to construct a conceptual model with the minimum number of land segments needed to simulate the hydrologic processes (Dinicola 1990). Factors that influence land segmentation for a typical HSPF model application include the meteorological forcing terms, characteristics of the watershed system itself (e.g., topography, geology, soils, land use, channel properties, etc.), and calibration endpoints, among others. A given land segment may contain one or many modeled sub-watersheds. A set of pervious land areas, directly connected impervious land areas, and reaches that may be open or closed channels, or completely mixed impoundments, constitute the land area and hydrography for a given land segment. A drainage area, or a sub-watershed, is associated with each specified reach.

The HSPF model code consists of three application modules (PERLND, IMPLND, RCHRES) and five utility modules (COPY, PLTGEN, DISPLY, DURANL, GENER, MUTSIN). The PERLND and IMPLND application modules simulate runoff and water quality constituents from pervious and directly connected impervious land areas in the watershed, respectively. Within a given drainage area or sub-watershed, the RCHRES module is used to route runoff and water quality constituents simulated by the PERLND and IMPLND modules through a single reach of open or closed channel or a completely mixed impoundment. Bicknell et al. (1996) and Donigian et al. (1995) provide graphical summaries that describe the structure and contents of the PERLND, IMPLND, and RCHRES application modules. Bicknell et al. (1996) and Donigian et al. (1995) provide detailed descriptions of the individual compartments within the PERLND, IMPLND, and RCHRES application modules.

The five utility modules are used to manage model input and model-generated time series data that are typically stored by an HSPF model user in one or more Watershed Data Management (WDM) files. A WDM file is a binary, direct-access file format that supports efficient storage and retrieval of time series data. Bicknell et al. (1996) and Donigian et al. (1995) provide descriptions of the five utility modules in HSPF.

The HSPF application modules contain compartments that completely account for the land-side components of the hydrologic cycle, and, as noted above, these compartments descend from the Stanford Watershed Model. The ATEMP compartment of the PERLND application module adjusts the input air temperature time series assigned to a given pervious land area based on the elevation difference between the station and the pervious land area. The SNOW compartment of the PERLND application module may simulate snow accumulation and melt by either an energy balance approach or a temperature index/degree-day method.

The PWATER compartment of the PERLND application module models the complete land-side water budget for a pervious land area, and it is the key compartment in the PERLND module in that it is the basis for all subsequent water quality simulation. Precipitation falling on the land surface is first intercepted by vegetation. Interception storage in HSPF is modeled as a reservoir 
that must first be filled before any precipitation can reach the ground. The modeler specifies the interception storage capacity, and it can vary seasonally. Excess precipitation reaching the land surface is temporarily placed in surface detention storage, from where it will either enter the upper zone as potential direct runoff or it will infiltrate into the subsurface. The partitioning between these two pathways is a function of the soil moisture and the infiltration rate. Potential direct runoff is further partitioned as either direct surface runoff, interflow runoff, or upper zone storage. The amount of direct surface runoff within a particular time step is a function of slope, roughness (which can vary seasonally), and distance to a first-order stream. Interflow runoff is stored in a reservoir that empties based on a specified decay rate. Both the inflow and decay rate for interflow can vary seasonally. Upper zone storage represents ditches, swales, or depressions in the watershed surface, and it can vary seasonally. Water in the upper zone storage can either evaporate, percolate to the subsurface, or become direct runoff or interflow during the next time step. The partition between upper zone storage and direct surface runoff is a function of upper zone storage and its nominal value. Infiltrated water is routed to either lower zone storage, active groundwater storage, or deep inactive groundwater. Water is first put in the lower zone storage. Once the lower zone storage is satisfied, the remaining water is partitioned between deep/inactive groundwater and active groundwater storage. Active groundwater is stored in a reservoir and released as baseflow based on a specified groundwater recession parameter. PWATER attempts to meet the input evapotranspiration demand by evaporating water from five possible storages in the following sequence: baseflow, interception storage, upper zone storage, active groundwater, and lower zone storage. Each storage has a user-specified resistance to evaporation. The resistance to evaporation for the lower zone storage can vary seasonally.

For a pervious land area, HSPF attempts to account for both the temporal and spatial dimensions of the infiltration process. The infiltration process is modeled based on Philip's equation, with cumulative infiltration represented as the ratio of the lower zone storage to its nominal storage value. The spatial distribution of infiltration over a pervious land area is modeled by specifying a linear probability density function for the infiltration capacity. Inflow to the interflow reservoir is modeled in a manner quite similar to the approach utilized to model infiltration. In particular, what constitutes interflow is assumed to be proportional to the local infiltration capacity. The fraction of the remaining subsurface water goes to either lower zone storage or groundwater (active and/or inactive) based on the ratio of lower zone storage and its nominal value.

The SEDMNT compartment of the PERLND application module models sediment production and removal for pervious land areas in the watershed. The processes of detachment, wash-off of the detached sediment, and scour of the soil matrix are all modeled using simple two-parameter relationships of the form

$$
e=a q^{b}
$$

where $e$ represents detachment, wash-off, or scour; $a$ and $b$ are parameters; and $q$ is either a model input or a model-generated quantity. For detachment, $q$ is the rainfall rate; whereas, for wash-off and scour, $q$ is the model-computed overland flow rate. The sediment load calculated from the land surface is a total load (i.e., there is no division into sand, silt, and clay classes). Detached sediment storage may be modified by two additional fluxes, lateral inflow from an 
upslope land area and/or net vertical sediment input resulting from wind and/or human activities. The soil matrix is assumed to have infinite storage.

The PQUAL compartment of the PERLND application module simulates water quality constituents in the outflows from a pervious land area (i.e., overland flow, interflow, baseflow, wash-off of detached sediment, and scour of the soil matrix) using straightforward relationships based on water and/or sediment yield. Constituents assumed to be transported with sediment may be modeled by specification of potency factors that relate constituent strength proportionally to the sediment removal computed in the SEDMNT compartment of the PERLND application module. General pollutant accumulation and wash-off equations, which relate constituent washoff to constituent storage and computed surface runoff, are another mechanism for modeling generalized water quality constituents. A user-specified parameter in the second approach allows for modeling a "first flush" effect. PQUAL allows for the specification of monthly concentrations for the subsurface outflows (i.e., interflow and baseflow).

The MSTLAY, PEST, NITR, PHOS, and TRACER compartments of the PERLND application module support the detailed simulation of solute transport, pesticides, nitrogen, phosphorous, and conservatives, respectively. Together, these compartments constitute what is referred to as the AGCHEM section of the HSPF model due to their principal use in modeling agricultural chemicals. The PERLND application module contains two additional compartments, PSTEMP and PWTGAS, which simulate soil temperature and surface runoff water temperature and gas concentrations, respectively.

The IMPLND application module is used for impervious land areas where little or no infiltration occurs, principally urban land categories. The ATEMP, SNOW, IWATER, SOLIDS, IWTGAS, and IQUAL compartments within the IMPLND module are very similar in function and structure to the ATEMP, SNOW, PWATER, SEDMNT, PWTGAS, and PQUAL compartments in the PERLND module, respectively.

The RCHRES application module contains compartments that simulate hydraulics, water temperature, noncohesive and cohesive sediment, pesticides, nutrients, biochemical oxygen demand, phytoplankton, zooplankton, dissolved oxygen, and $\mathrm{pH}$, among others. HSPF provides the user with the capability to simulate any water quality constituent by specifying its sources, sinks, decay properties, and advective behavior. Flow through a RCHRES is assumed to be unidirectional. All inputs to a reach are assumed to enter at a single upstream point. The outflow from a reach, or from a completely mixed lake, may be distributed across several targets to represent normal outflow, diversions, and multiple gates on a lake or reservoir.

Support Software. The EPA, USGS, and others have developed several software programs to support HSPF model development and application. Among others, these include IOWDM (http://water.usgs.gov/software/iowdm.html), ANNIE (Flynn et al. 1995), METCMP (Flynn and Lumb 1991), WDMUtil (USEPA 1999a), HSPFParm (Donigian et al. 1999), HSPEXP (Lumb et al. 1994), WinHSPF, GenScn (Kittle et al. 1998), the HSPF interface within the Watershed Modeling System (WMS) developed jointly by the USACE Waterways Experiment Station and Brigham Young University (Brigham Young University 1999), and the model-independent parameter estimation tool PEST (Doherty 2002; Doherty and Johnston 2003). With the exception 
of the WMS, all of the above-noted software is in the public domain. In addition, HSPF is the nonpoint source model interfaced within the public domain Better Assessment Science Integrating Point and Nonpoint Sources (BASINS) system developed and freely distributed by the EPA Office of Water to support Total Maximum Daily Load (TMDL) analysis nationwide.

The IOWDM, ANNIE, and WDMUtil utility software packages are typically used to input and subsequently manage HSPF model input, calibration, and model-generated output time series data in a Watershed Data Management (WDM) file. The METCMP software system is typically used to fill in missing precipitation data and/or disaggregate meteorological data. Much of the functionality of the DOS-based programs IOWDM, ANNIE, and METCMP is now contained within the possibly more usable Windows-based utility software WDMUtil. However, there are still some time series data management tasks that are more easily performed, or that are only possible, using the predecessor DOS-based tools.

The HSPF Parameter Database (HSPFParm) is a Windows-based software package that was designed to be a source for identifying reasonable initial values, and possibly also expected parameter ranges, for model parameters prior to initiating the calibration process. It provides an HSPF modeler interactive access to calibrated parameter values from previous applications of HSPF across North America. Although Donigian et al. (1999) noted that "the parameter values, contained in the database, characterize a broad variety of physical settings, land use practices, and water quality constituents," examination of Figure 1, a screenshot of HSPFParm depicting all locations contained in its database, clearly indicates that the current database may be of limited utility to support practical HSPF application for many areas of the United States. Hydrologic calibration is typically performed manually, often utilizing the expert system calibration tool HSPEXP. HSPEXP produces a standard set of mass balance, statistical, and hydrograph comparisons that greatly facilitate manual HSPF hydrologic model calibration. The HSPEXP system also provides advice on parameter adjustments related to various user-specified error criteria for deciding whether each phase of calibration is satisfactory. HSPEXP is only designed to support iterative manual HSPF calibration for the hydrologic simulations and does not deal with water quality processes.

GenScn is a public domain graphics-based management modeling environment that supports scenario analysis (assessing the hydrologic and water quality impacts of land use change, for example), best management practice (BMP) analysis, and time series data analysis for the HSPF model, among others. With GenScn, for a given HSPF model, one may graphically select a single sub-basin/reach/outlet or multiple sub-basins/reaches/outlets, one or multiple modeled scenarios, and desired constituents, and subsequently retrieve all of the time series data that have been stored for the selected modeled location(s), scenarios, and constituents. Thereafter, one may graphically compare the selected time series data, perform statistical comparisons, and/or export the data for further analysis, in a spreadsheet, for example. GenScn also possesses animation capabilities, allowing one to visualize the spatial and temporal character of various HSPF model output. In addition, GenScn gives the user full access to the capabilities of the HSPF model. For example, the GenScn graphical user interface allows one to easily select a pre-existing HSPF model scenario (e.g., maybe the "calibrated" scenario related to the HSPF model under consideration), activate it, and perform a new modeling scenario on the fly, with new time series data set numbers in the associated model output WDM file automatically generated. 


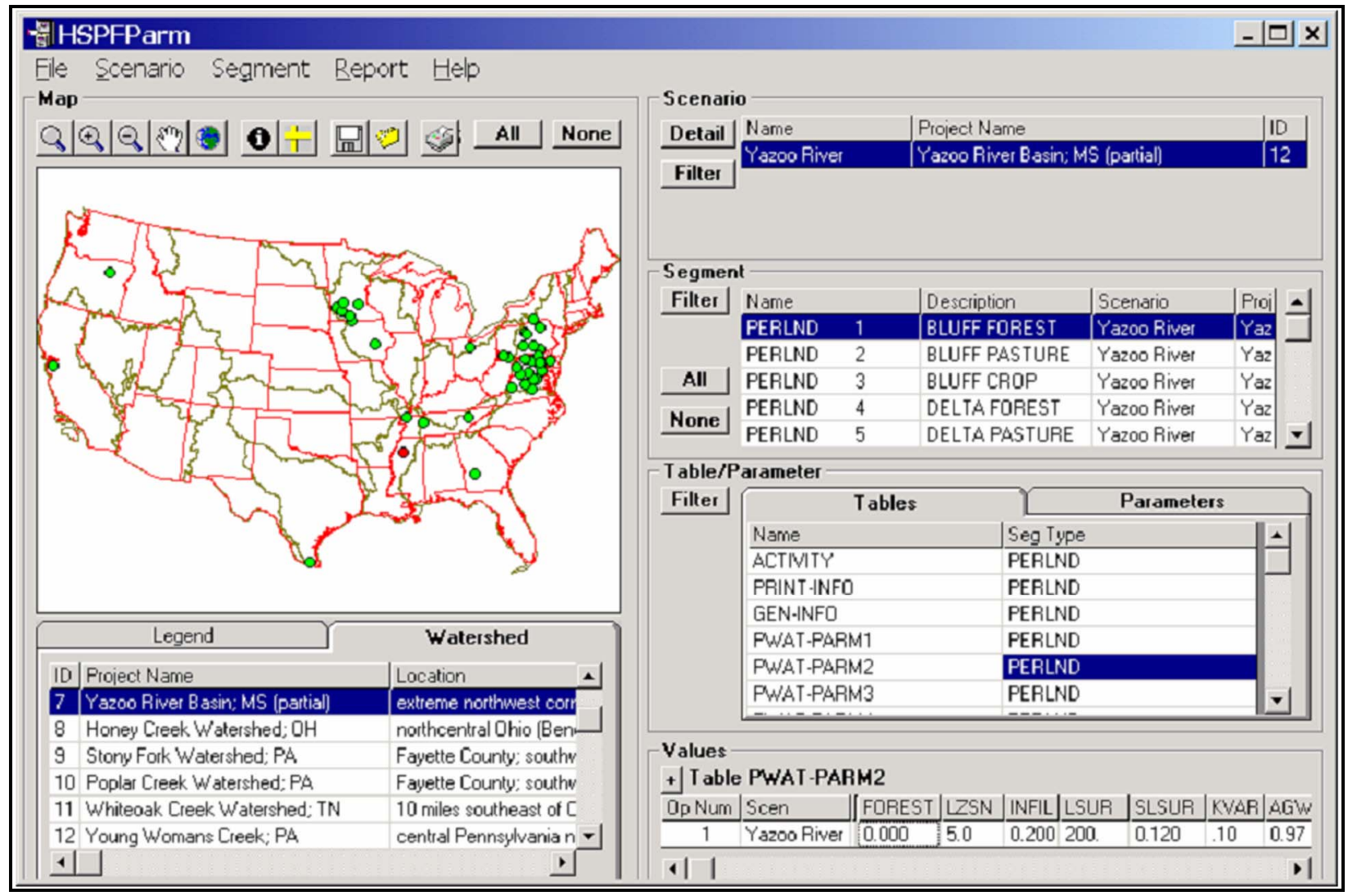

Figure 1. Screenshot graphically depicting all of the locations that constitute the HSPFParm database

The ability to efficiently construct and initially parameterize the Users Control Input (UCI) file, the main HSPF model input file, using readily available and/or project-specific GIS data coverages is the principal strength of the HSPF model interface in WMS. In particular, watershed delineation (if not already performed), or easy incorporation of a pre-existing watershed delineation, land segmentation, computation of the areal distribution of land use within each modeled sub-watershed, determination of the model topology, and graphical/conceptual model support for construction of a complete HSPF model UCI file are some of the current notable strengths of the HSPF model interface in the WMS.

PEST is a public domain model-independent parameter estimator with advanced predictive analysis and regularization features. It utilizes a robust implementation of the Gauss-MarquardtLevenburg method. PEST will adjust model parameters and/or excitations until the fit between model outputs and laboratory or field observations is optimized in the weighted least squares sense. A suite of PEST model utility software is available to be used as part of the calibration and predictive analysis process, some specific to HSPF/PEST linkage and application. PEST, together with its utility software, allows one to incorporate into the parameter estimation process, among others,

- Known/perceived parameter bounds.

- Known/perceived parameter relationships. 
- "Volumetric observations" (e.g., over the entire simulation time period, monthly volumetric readings, and/or one or a number of discrete events).

- One's intuition or indirect knowledge (for example, to determine the relative magnitudes of different flow components (interflow, baseflow, surface runoff)).

- Exceedence-time characteristics.

- (Prior) information available from outside of the parameter estimation process about what value a parameter should take.

Hence, "reality" and "plausibility" checks can, and should, be implicitly incorporated into the PEST/HSPF parameter estimation process, thus allowing such an endeavor to remain within the bounds of historical/conventional HSPF model practice.

PEST parameter estimation mode output includes, among other items, the number of model parameters considered, a summary of the fixed and tied parameters, a written summary of the parameter estimation process, final optimization results, confidence bounds for the estimated parameters, the computed correlation coefficient for the parameter set that minimizes the objective function, parameter correlations, and parameter sensitivities, among others. Tied parameters are those that "piggyback" on their parent parameter during the parameter estimation process. PEST does not estimate a value for a tied parameter; rather it adjusts the parameter during the estimation process such that it maintains the same ratio with its parent parameter as that provided through the initial estimates of the respective parameters. Fixed parameters take no part in the parameter estimation process.

In addition to some of the above-noted capabilities, PEST with HSPF also allows the user to assess the clearly needed (National Research Council 2001) implications of parameter uncertainty (Whittemore and Beebe 2000) on HSPF model predictive uncertainty. In particular, PEST's predictive analysis mode allows the user to examine the range of uncertainty of a key HSPF model prediction (e.g., a maximum daily constituent loading, peak discharge, minimum flow, maximum water temperature, minimum DO, ...) while maintaining the model in a calibrated (or almost calibrated) state.

PEST also includes advanced regularization capabilities. Use of this functionality makes PEST unique among environmental model calibration software. It allows PEST to work in highly parameterized modeling contexts; problems with parameter nonuniqueness are overcome through enforcement of constraints on parameter values, or on relationships between these values; ideally, these constraints should be such that they are in harmony with a modeler's current understanding of processes operative in an area. Estimating a parameter suite allows the model to replicate historical data to a user-specified tolerance, and PEST minimizes deviations of parameter values from this "preferred parameter condition." This ability to estimate large numbers of parameters in ways that are both numerically stable and hydrologically/hydraulically reasonable, allows PEST to work well in the complex modeling contexts with which modern-day modelers are constantly faced. At present, the PEST/HSPF linkage is a DOS-based, commandline-driven process. There is a need to make the powerful PEST/HSPF linkage more accessible/usable to the HSPF modeler through the generation of application-specific guidance documents and graphical interface development. 
HSPF model application-specific software support tools are also available; for example, the Bacterial Indicator Tool (USEPA 2000a) and the spreadsheet tool TMDLUSLE (USEPA 2001), both of which are freely available from the EPA Web pages.

Capabilities and Limitations. Donigian et al. (1995) listed several potential applications and uses of the HSPF model:

- Flood control planning and operations.

- Hydropower studies.

- River basin and watershed planning.

- Storm drainage analyses.

- Water quality planning and management.

- Point and nonpoint source pollution analyses.

- Soil erosion and sediment transport studies.

- Evaluation of urban and agricultural best management practices (BMPs).

- Fate, transport, exposure assessment, and control of pesticides, nutrients, and toxic substances.

- Time-series data storage, analysis, and display.

USACE and USEPA (2000) list documented strengths and weaknesses of the HSPF model. Strengths include its comprehensive treatment of watershed-scale hydrologic and water quality processes, flexible design, widespread applicability, sustained support by both the EPA and USGS, and its companion WDM file and utility software. Weaknesses listed include, among others, its lumped parameter approach, unidirectional treatment of flow hydraulics, limited treatment of the urban drainage system, lack of comprehensive parameter guidance, extensive data requirements, and the user training that is typically required to operate the model.

One of the notable strengths of the HSPF model is its ability to account for the land use distribution within a given modeled watershed. This information, or a blending of this information with other data describing the watershed, serves as a basis for part of the model parameterization process. However, the available guidance information and tools do not support a comprehensive model parameterization effort for a watershed with mixed land uses. For example, the expert system tool HSPEXP does not provide expert advice related to the discernment of parameter differences across land uses. As a result, current practice with HSPF for parameterizing across land uses is a fairly heuristic exercise. Furthermore, the expert system tool HSPEXP does not provide any water quality model parameter estimation support. Clearly, HSPF model parameterization for a typical model deployment is a difficult task alone, despite the availability of support utilities such as HSPFParm (Donigian et al. 1999). The comments provided below, from Munson (1998), clearly underscore this point.

It quickly became apparent that little data exists to distinguish the hydrologic characteristics among land uses. Indeed, this has always been problematic in HSPF [18]. When setting parameters such as lower zone storage, for example, there is no empirical data to support different LZSN values for different land uses. It makes intuitive sense that wetlands should be able to store more water than forest, which stores more than residential land. However, the 
magnitudes of these differences can only be guessed at. If the average calibrated value of LZSN is about 15 inches, then any combination of LZSN values should give the same results if they average to fifteen.

Munson's (1998) comments above are consistent with Whittemore and Beebe (2000) and (Whittemore 2001), who both also noted the issue of HSPF model parameter nonuniqueness, and they dovetail well with the National Research Council's (2001) recent recommendation that "guidance/software needs to be developed to support uncertainty analysis" as part of the TMDL modeling process. Linking the model-independent parameter estimation tool PEST (Doherty 2002) with HSPF is one path towards a more science-based approach to support HSPF model parameter estimation and predictive analysis for mixed land use watersheds.

MODEL DEVELOPMENT AND CALIBRATION: USACE and USEPA (2000) list the major steps in the HSPF model simulation process:

- Problem definition.

- Modeling strategy.

- Operational aspects.

- Collection and development of time series data.

- Characterization and segmentation of the watershed.

- Calibration and validation of the model.

These major model simulation steps require approximately $5,10,10,30,15$, and 30 percent of the total project effort, respectively.

Data Requirements. Data requirements for an HSPF model application can be grouped into three broad categories (Munson 1998):

- Physical watershed-specific data.

- Meteorologic data.

- Calibration data.

Physical watershed-specific data are necessary to adequately describe the watershed. Physical watershed-specific data include elevation, channel geometry, soils, vegetation, and land use and land cover (LULC), among others. These data can be obtained from Geographic Information System (GIS) databases, topographical maps, field observations, regulatory agencies, and historical records. A GIS allows for mapping and evaluation at multiple scales. Meteorologic time series data requirements for the HSPF model vary depending upon which processes are modeled. USACE and USEPA (2000) list the meteorologic time series data requirements for various individual compartments within the PERLND, IMPLND, and RCHRES application modules. In general, HSPF requires six meteorologic time series to model streamflow. These include precipitation, potential evapotranspiration, air temperature, dewpoint temperature, wind speed, and solar radiation. However, if snow accumulation and melt are not simulated, the meteorologic time series data requirements include precipitation and potential evapotranspiration. Water quality simulations also require time series of cloud cover. Empirical data are 
required to calibrate and validate processes simulated by HSPF. These data are not input to HSPF, but are used to evaluate model performance.

Development. The IOWDM, ANNIE, and WDMUtil utility software packages are typically used to input and subsequently manage HSPF model input, calibration, and model-generated output time series data in a Watershed Data Management (WDM) file.

For a given modeled watershed, the channel network must be divided into reaches based on the HSPF constraint that there is a minimum length which keeps the Courant number smaller than one (Lohani et al. 2000; Munson 1998). Reach boundaries are also placed at physical structures such as dams, tributaries, and lake inlets and outlets. The required rating table for a reach can be obtained from stream cross-section data and utilization of Manning's equation or specification of an outflow demand which may be a function of volume and/or time. USEPA (1999b) provides guidance on the generation of a rating table for a reservoir. The watershed contributing to each reach can subsequently be delineated using readily available digital elevation models (DEMs) and GIS or GIS-compatible processing techniques; for example, the tools within the Watershed Modeling System (Brigham Young University 1999).

Land segmentation is specified to divide the watershed into individual land segments that are assumed to produce a homogeneous hydrologic and water quality response. Land segmentation, together with the specification of land use classes to model, dictates how an HSPF model will ultimately be parameterized. Land Use and Land Cover (LULC) data are typically used to define pervious and directly connected impervious land areas within each land segment, which may contain one or many modeled sub-watersheds. Typical HSPF model applications define approximately five to six distinct land use classes within each modeled land segment (Northwest Hydraulic Consultants Inc. 1993a, 1993b; Munson 1998; HydroGeoLogic, Inc. and AQUA TERRA Consultants 1999; Lohani et al. 2000; Bergman and Donnangelo 2000).

Calibration. A reliable water quality model depends upon a prior satisfactory hydrologic model calibration and validation. For HSPF, a fair amount of guidance material and support software is available, in the public domain, to support a hydrologic model calibration and validation exercise. This material includes:

- US EPA BASINS Technical Notes (http://www.epa.gov/ost/basins/bsnsdoc.html\#tech).

- Web-based hydrologic calibration guides (http://www.epa.gov/waterscience/ftp/basins/training/tutorial/di.htm, http://www.hydrocomp.com/jour4b.htm).

- The expert system tool HSPEXP (Lumb et al. 1994).

- The Windows-based HSPF Parameter Database tool HSPFParm (Donigian et al. 1999).

- Past documented HSPF studies.

- Research articles; for example, Donigian (2002).

Donigian (2002) provided a fairly comprehensive summary of issues related to watershed model calibration and validation based on more than 20 years of experience with the HSPF model. 
Several HSPF model parameters are not available from field data, and must be determined through model calibration. HSPF hydrologic model calibration is typically performed manually by comparing simulated and observed flow volumes for various runoff categories: total runoff, 50 percent lowest flows, 10 percent highest flows, storm flows, and seasonal runoff. Other criteria that are also used to support the manual calibration of an HSPF model include:

- Visually inspecting the match of simulated and observed flows.

- Validation of the calibration results.

The expert system calibration tool HSPEXP (Lumb et al. 1994) is a tool that is often used to support the manual hydrologic model calibration for an HSPF model. HSPEXP produces a standard set of mass balance, statistical, and hydrograph comparisons that facilitate manual HSPF hydrologic model calibration. The HSPEXP system also provides advice on parameter adjustments related to various user-specified error criteria for deciding whether each phase of calibration is satisfactory. Accuracy of the simulations is measured as the volume error percentage for the various runoff categories. Volume error is defined as the ratio of the difference between simulated and observed flows, expressed as a percentage of observed volumes. The default error criteria within the HSPEXP system can be adopted, or modified, to quantify the simulation errors. The default error criteria for HSPEXP are 10 percent error allowed in total volume, volume of 50 percent lowest flows, and seasonal error, and 15 percent error allowed in 10 percent highest flows and storm volumes. A model calibration would be assumed to be complete when simulated volumes for each runoff category fall within the specified error limits. The HSPF Application Guide states that "calibration should be based on several years of simulation (3 to 5 years is optimal) in order to evaluate parameters under a variety of climatic, soil moisture, and water quality conditions." Donigian (2002) provided correlation coefficient and coefficient of determination value ranges for assessing hydrologic model performance for daily and monthly flows. A "good" HSPF hydrologic model calibration would have r-squared value ranges at monthly and daily timescales of approximately $0.75-0.85$, and $0.70-0.80$, respectively.

A standard HSPF hydrologic model calibration is divided into four phases (HydroGeoLogic, Inc. and AQUA TERRA Consultants 1999):

- Establish the annual water balance.

- Adjust low flow / high flow distribution.

- Adjust storm flow / hydrograph shape.

- Make seasonal adjustments.

Four parameters significantly influence the annual water balance: INFILT, LZSN, UZSN, and LZETP (Munson 1998; HydroGeoLogic, Inc. and AQUA TERRA Consultants 1999; Bergman and Donnangelo 2000). The parameters INFILT, AGWRC, and BASETP significantly influence the low flow / high flow distribution (HydroGeoLogic, Inc. and AQUA TERRA Consultants 1999). The parameters UZSN, INTFW, and IRC significantly influence stormflow volumes and hydrograph shape (Munson 1998; HydroGeoLogic, Inc. and AQUA TERRA Consultants 1999). Seasonal adjustments are generally accomplished by using time varying values for the parameters CEPSC, LZETP, and UZSN. Adjustments to KVARY and BASETP may also be 
used (Munson 1998; HydroGeoLogic, Inc. and AQUA TERRA Consultants 1999). Munson (1998), HydroGeoLogic, Inc. and AQUA TERRA Consultants (1999), Bergman and Donnangelo (2000), and USEPA (2000b), among others, all provide excellent descriptions of these HSPF water budget parameters, and others, and their impact on the various phases of an HSPF hydrologic model calibration.

Uncertainty Analysis. Beven and Binley (1992) developed the Generalized Likely Uncertainty Estimation (GLUE) procedure as a method for model calibration and uncertainty estimation. The GLUE methodology of Beven and Binley (1992) does not acknowledge a unique optimal parameter set. Instead, Monte Carlo simulation (MCS), specified probability distributions for each parameter (typically, uniform distributions are utilized), a likelihood measure or set of likelihood measures, and an acceptance/rejection criteria are used to generate, evaluate, and accept or reject parameter sets as simulators of a basin's response. The rejected models are assumed "nonbehavioral" and their likelihood measures are set to zero; thereby removing them from the subsequent analysis. The likelihood measures for the accepted parameter sets are utilized to estimate the uncertainty of the model's predictions. Parameter interaction and uncertainties in the input and boundary data are assumed to be implicitly reflected in the likelihood measure. Computational demands are high for the GLUE procedure. Beven $(1998,2001)$ discuss four alternative methods for updating likelihood measures as additional data become available. The use of Bayes' equation has received the most attention.

For the reasons outlined below, GLUE is inherently attractive to apply to HSPF to support calibration and uncertainty estimation.

1. HSPF hydrologic model calibration alone is a manual, iterative, time-consuming process, even when using the expert system calibration tool for HSPF, HSPEXP (Lumb et al. 1994).

2. The expert system calibration tool for HSPF, HSPEXP, is only designed to support iterative manual HSPF calibration for the hydrologic simulations and does not deal with water quality processes.

3. HSPF is not a computationally demanding model.

4. It is straightforward to:

a. Write software to generate multiple Users Control Input (UCI) files, the main HSPF model input file, using MCS and specified parameter ranges.

$b$. Prepare the WDM file(s) to receive the output from the HSPF models or directly generate ASCII file output from the HSPF models.

c. Run the HSPF models in batch mode on a personal computer.

d. Write software to process and evaluate the output data from the HSPF models.

5. Available procedures for updating the GLUE likelihood measures, such as Bayes' equation, allow one to easily:

a. Incorporate water quality data into the model calibration process.

$b$. Consider land use change within the watershed during the model calibration process.

c. Incorporate data with missing records into the model calibration process. 
The GLUE procedure of Beven and Binley (1992) was applied to an HSPF hydrologic model of the Goodwin Creek watershed, an 8.26-square-mile experimental watershed operated by the Agricultural Research Service (ARS) of the United States Department of Agriculture (USDA). The Nash and Sutcliffe (1970) efficiency criterion, ES, was used for the likelihood measure. Initially, $1000 \mathrm{MCS}$ were performed. Twelve parameters were allowed to vary across the five different land use classes or hydrologic soils groups (LZSN, AGWRC, INFILT, DEEPFR, BASETP, AGWETP, CEPSC, UZSN, NSUR, INTFW, IRC, LZETP), with two additional parameters allowed to vary monthly across two of the land use classes (CEPSC and LZETP). Uniform distributions were utilized for sampling, and sampling ranges were based on guidance provided in USEPA (2000), Munson (1998), and USACE and USEPA (2000). A dotty plot of the results from the 1,000 MCS's is shown in Figure 2. A dotty plot is a projection of the MCS points on the performance measure surface onto separate parameter dimensions (Beven 2001). In an effort to reduce the number of parameters involved, an additional MCS experiment was performed. For this case, the HSPF model of Goodwin Creek involved one land segment and only one pervious land area. Dotty plots of the results from the second MCS experiment are shown in Figures 3 and 4.

Goodwin Creek is a tributary of Long Creek, which flows into the Yocona River, one of the main rivers of the Yazoo River Basin. The Goodwin Creek watershed is located in Northern Mississippi, approximately 60 miles south of Memphis, Tennessee. Goodwin Creek is divided into 14 nested sub-watersheds with a flow measuring flume constructed at each of the subwatershed outlets. The drainage areas above the gaging sites range from 0.63 to 8.26 square miles. Thirty-one standard recording rain gages are uniformly located within and just outside of the watershed.

The initial MCS experiment resulted in only one of the models having a Nash and Sutcliffe efficiency score greater than zero, and that model possessed a low efficiency score of 0.125 . This extremely low hit-to-miss ratio for an HSPF model of "typical" complexity is disappointing. While based on a very limited number of Monte Carlo simulations, the results from the second MCS experiment shown in the dotty plots of Figures 3 and 4 did not seem to overtly suggest model equifinality as described by the authors of GLUE. The results obtained from the application of GLUE/MCS to the HSPF model of Goodwin Creek are very preliminary and further examination is required, and will be performed, to assess the utility of GLUE and/or MCS as a tool to support HSPF model calibration and uncertainty estimation.

A computationally tractable and highly usable approach, that is documented and readily available in the public domain, for "calibrating" and quantifying HSPF model predictive uncertainty is to couple the previously described model-independent parameter estimation tool PEST with HSPF. 
Figure 2. Dotty plot of first MCS experiment
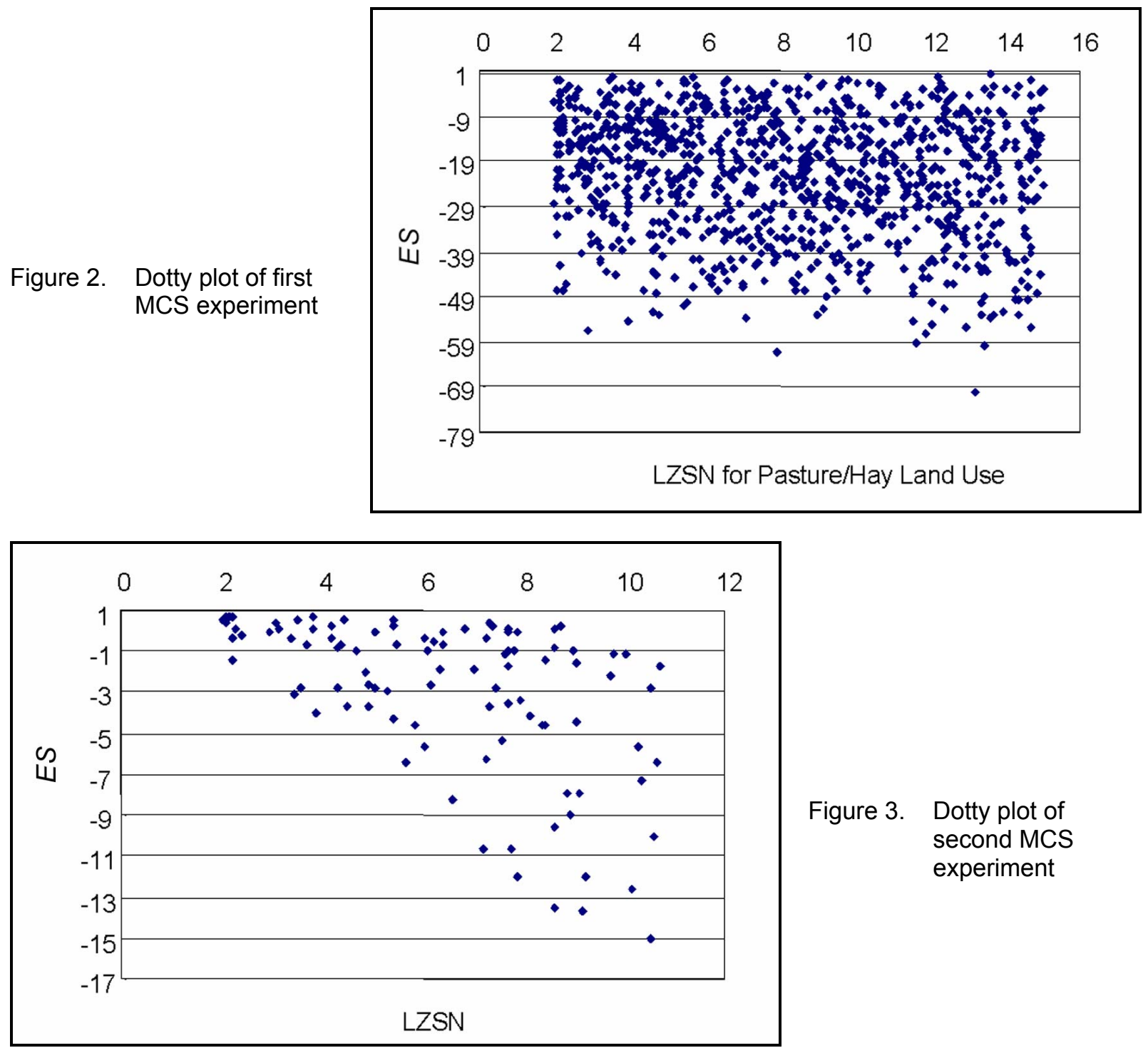

Figure 3. Dotty plot of second MCS experiment

Figure 4. Dotty plot of second MCS experiment

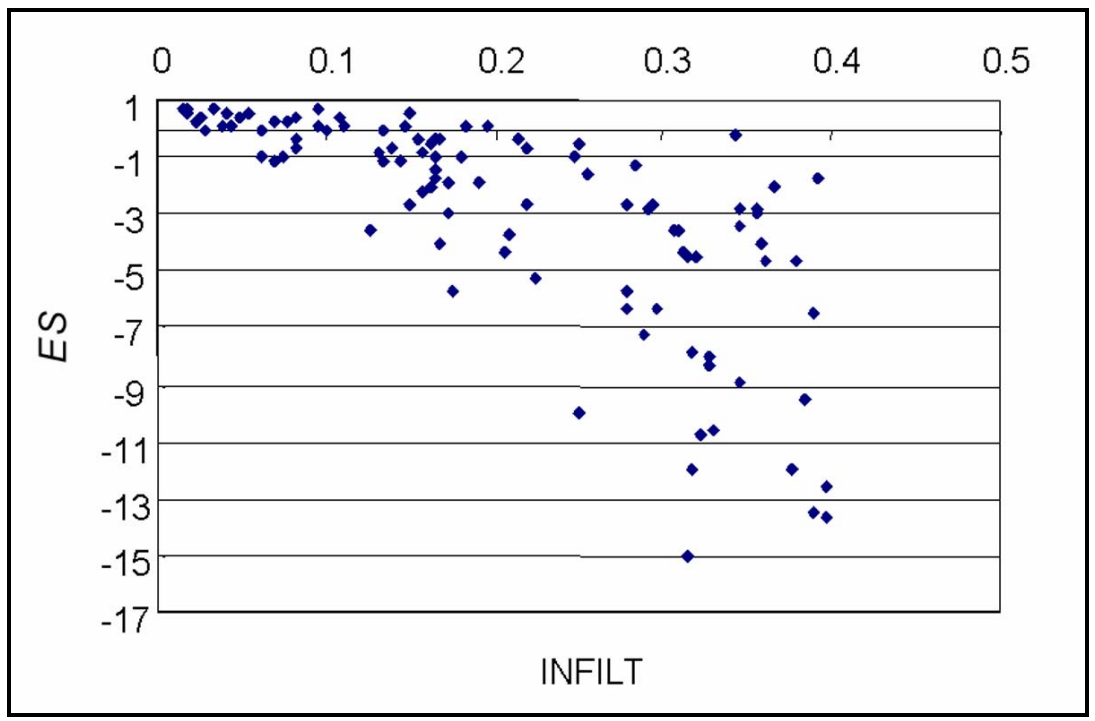


CASE STUDY APPLICATION - BAUTISTA CREEK: The Los Angeles District Corps of Engineers-Regulatory Branch is developing a Special Area Management Plan (SAMP) for the San Jacinto River basin in Riverside County, California. The purpose of the SAMP is to "develop and implement a watershed-wide aquatic resource management plan and implementation program, which will include preservation, enhancement, and restoration of aquatic resources, while allowing reasonable and responsible economic development and activities within the watershed-wide study area" (U.S. army Engineer District, Los Angeles, 2000).

As part of the SAMP for the San Jacinto River basin, Waters of the United States (WoUS) in the San Jacinto were delineated using a unique planning level delineation procedure (Lichvar 2000). In addition, riparian ecosystems were assessed at the riparian reach spatial scale using indicatorbased integrity indices of hydrology, water quality, and habitat (Smith 2000). Supplementary hydrologic modeling studies (Smith et al. 2002) were included in the SAMP to:

1. Provide additional characterization information on baseline conditions of the study area.

2. Develop measures or design parameters to minimize impacts to aquatic resources as well as design parameters for the establishment of a successful aquatic reserve system.

3. Provide information that could be used by the County of Riverside in the context of flood control, planning, erosion and sediment transport, point and non-point source pollution, Total Maximum Daily Loadings (TMDLs), Best Management Practices (BMPs), as well as other state, local, and federal regulatory compliance programs.

4. Provide an opportunity to evaluate the indicators and indices currently being used to assess riparian ecosystems, all of which are scaled to a reference condition designated as "culturally unaltered."

The discussion presented in this section is principally directed to item 4 noted directly above; that is, hydrologic model simulation support to an ecologically based riparian ecosystem assessment and recovery technology. The evaluation has partly consisted of assessing the hydrologic simulation model parameters' sensitivities and correlations during the parameter estimation process. A subsequent mapping of the hydrologic simulation model parameters to the indices would then enable one to eliminate possible redundancies present in the index level model. Due to the above-noted scaled nature of the indices, after the simulation model was calibrated to current conditions, the evaluation also consisted of a hydrologic model scenario simulation representative of the "culturally unaltered" system condition. Observed discrepancies between the scenario simulation differences (i.e., difference of the calibrated and "culturally unaltered" simulation model results) and the index level model results could then be viewed as an opportunity to investigate if there are additional indices that need to be included in the index level model to ensure a robust assessment of the integrity of each riparian reach.

In support of the supplementary hydrologic studies for the SAMP, an HSPF model was developed, calibrated, and verified to available mean daily streamflow data for the approximate $120-\mathrm{km}^{2}$ Bautista Creek subwatershed of the San Jacinto river basin in Riverside County, California. Scenario analyses were subsequently performed to simulate the effects of land use change. In particular, the HSPF model was developed and calibrated to recent land surface conditions and scenarios were subsequently performed to simulate a "culturally unaltered" 
condition and a projected build out ( 2020). The HSPF model simulation time step was $1 \mathrm{hr}$ and the time period for the model "calibration" and subsequent scenario simulations was January 01, 1990-December 31, 1993.

The Bautista Creek subwatershed of the San Jacinto River basin encompasses approximately $120-\mathrm{km}^{2}$, and elevations range from about 2,050 $\mathrm{m}$ above sea level at the high point on the southeastern edge of the watershed to $508 \mathrm{~m}$ at the watershed outlet. Figure 5 shows the relative locations of the San Jacinto River basin and the Bautista Creek subwatershed of the San Jacinto. Land use and land cover are principally shrub and brush; however, small pockets of agricultural activity and urbanization are present in the southeastern section of the watershed and also near the outlet. Table 1 summarizes the land use and land cover distribution in Bautista Creek for the "culturally unaltered," current, and future buildout conditions.

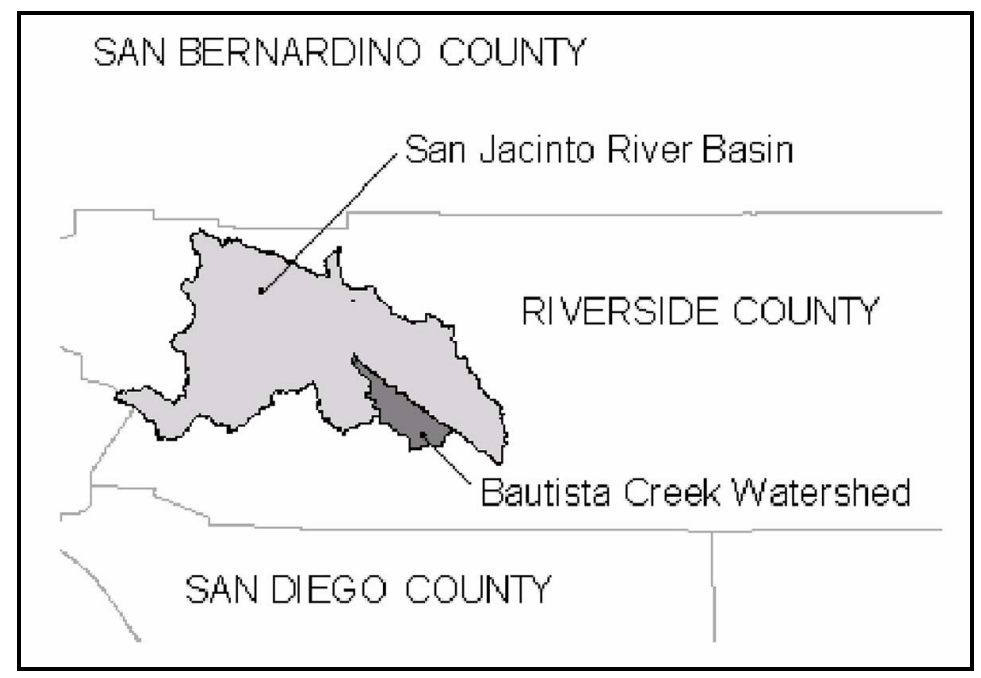

Figure 5. Relative locations of the San Jacinto and Bautista Creek

\section{Table 1}

Land Use and Land Cover Distributions in Bautista Creek

\begin{tabular}{||l|l|l|l||}
\hline \multirow{2}{*}{ Land Use } & \multicolumn{3}{|c||}{ Percent of Total Area } \\
\cline { 2 - 4 } & Historic & Current & Future \\
\hline \hline Agriculture & 0.00 & 1.23 & 1.21 \\
\hline Forests & 8.15 & 8.15 & 8.15 \\
\hline Grasslands & 2.85 & 1.75 & 1.69 \\
\hline Riparian & 1.30 & 1.30 & 1.31 \\
\hline Shrub & 87.69 & 87.28 & 86.40 \\
\hline Urban & 0.00 & 0.27 & 1.21 \\
\hline
\end{tabular}

The soils in the subwatershed are SCS hydrologic soil group C soils along the valley slopes and SCS hydrologic soil group A soils on the valley floor. Class A soils possess low runoff potential and consist of deep, well-drained to excessively drained sand and gravel, whereas class C soils possess a moderate to high runoff potential. It is presumed that precipitation falling on the valley slopes mainly results in overland flow, which infiltrates with direct precipitation through deep, 
unconsolidated pervious material on the valley floor. The United States Geological Survey (USGS) has operated a streamflow-gaging station on Bautista Creek at the head of a flood channel near Hemet (11070020) since October 1988. Figure 6 shows the location of the USGS streamflow-gaging station 11070020, the single National Climatic Data Center hourly precipitation gage, Hurkey Creek Park-4181, that was used to drive the HSPF model(s), and the watershed delineation/discretization for Bautista Creek. In Bautista Creek, model simulation results were required for comparison with the results from the index level method.

In support of the supplementary hydrologic studies for the SAMP, and for purposes of demonstrating some of the capabilities of an HSPF/PEST linkage to support HSPF model parameter estimation, PEST's parameter estimation mode of analysis was applied to a simplified HSPF model of Bautista Creek with the intent to discern parameter differences from the urban land use relative to all of the other modeled land uses within the system. In addition, PEST's parameter estimation mode of analysis was applied to quantify streamflow loss along the main stem of Bautista Creek. It is worth noting that this simplified HSPF model of Bautista Creek is of low complexity relative to a "typical" HSPF model application. The parameter estimation process was conducted by comparing three years (calendar years 1991-1993) of model simulated results against observed daily streamflow data from the USGS streamflow-gaging station on Bautista Creek at the head of the flood channel near Hemet (11070020). In particular, the specified multi-component objective function consisted of the daily streamflow data, aggregation of the daily streamflow data to a monthly time-step, and aggregation of the daily streamflow data to an annual time-step. Weights to each of these three groups of data were specified in a manner such that the parameter estimation engine saw each of them as of equal importance.

Figure 6. Location of USGS streamflow-gaging station 11070020

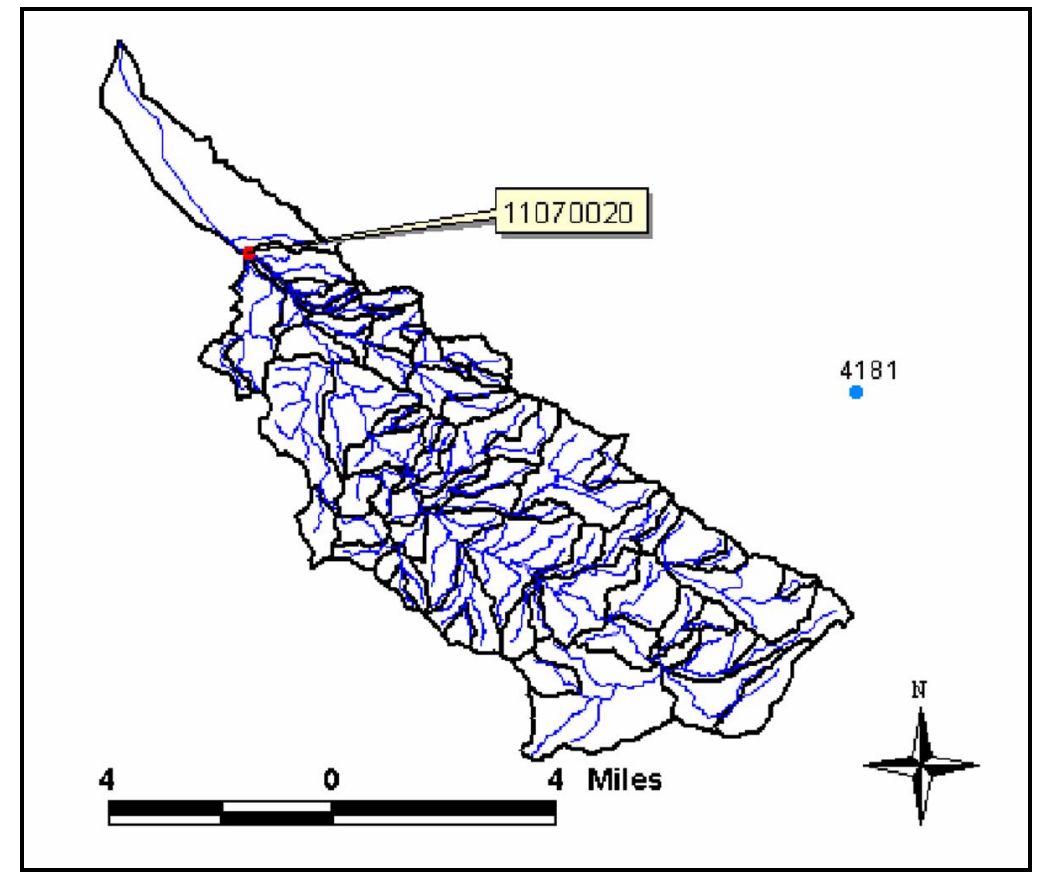

PEST's parameter estimation mode of analysis reduced the overall weighted objective function from an initial value of $7.02712 \mathrm{E}+11$ to $4.9274 \mathrm{E}+08$ in 322 model calls. Computed Nash and Sutcliffe efficiency scores of 0.76 and 0.90 were obtained from the optimized model at the daily 
and monthly timescales, respectively. The fair model performance was attributed to the fact that data from just a single precipitation gage, located well outside of the watershed, was available to support simulation for the entire $120-\mathrm{km}^{2}$ system.

Upon completion of the PEST parameter estimation run, the ratio of the highest to lowest eigenvalues associated with the resultant parameter covariance matrix was observed to be on the order of $10^{12}$. This significant observation indicated that the "normal matrix" (which is calculated from the Jacobian matrix, the matrix of partial derivatives of the observations with respect to the parameters) that must be inverted to compute the parameter upgrade vector, was ill-conditioned and that the parameter estimation process was experiencing difficulties as a result of parameter insensitivity and/or correlation. The normalized eigenvector associated with the largest eigenvalue, the direction of greatest parameter insensitivity, was dominated by a single component, and the parameter associated with that component was NSUR for the IMPLND application module. The normalized eigenvectors for the second and third largest eigenvalues, the next directions of greatest parameter insensitivity, were also observed to each be dominated by a single component. The parameters related to the dominant component of the normalized eigenvectors associated with the second and third largest eigenvalues were RETSC for the IMPLND application module and BASETP for the PERLND application module, respectively. Hence, based on also evaluating the resultant parameter correlation coefficient matrix, the insensitivity of a few parameters appeared to be the significant factor impairing the parameter estimation process for the simplified HSPF model of Bautista Creek. The parameter estimation process could possibly be improved by fixing one, two, or all three of the insensitive parameters noted above at values that are considered realistic for this hydrologic setting. It is interesting, but not surprising given the current land use distribution for Bautista Creek, that the only two IMPLND application module parameters that were considered were both observed to be poorly estimable. The poorly estimable nature of BASETP is better understood upon examination of the observed daily streamflow data, for 1991-1993, from the USGS streamflow-gaging station on Bautista Creek at the head of the flood channel near Hemet (11070020). Bautista Creek is an ephemeral system.

Table 2 summarizes the PEST computed composite parameter sensitivities for the simplified HSPF model of Bautista Creek. Examining Table 2, one can identify the most sensitive parameters for the hydrologic simulation model for Bautista Creek. For example, the three most sensitive parameters, in decreasing order, are the lower zone evapotranspiration parameter LZETP, the lower zone soil storage parameter LZSN, and the streamflow loss parameter $\mathrm{x}$. The PEST computed composite parameter sensitivities for the HSPF model of Bautista Creek that are presented in Table 2 confirm the observations that were made from the eigenvalues and eigenvectors associated with the parameter covariance

\begin{tabular}{|l|c||}
\hline \multicolumn{2}{|l||}{ Table 2 } \\
PEST Computed Parameter \\
Sensitivities for the Bautista \\
Creek HSPF Model \\
\hline \hline Parameter & Sensitivity \\
\hline \hline $\mathrm{x}$ & 118.860 \\
\hline imp & 52.8121 \\
\hline Izsn & 183.340 \\
\hline infilt & 73.2092 \\
\hline agwrctrns & 9.45310 \\
\hline deepfr & 44.0163 \\
\hline basetp & 1.33128 \\
\hline cepsc & 26.2252 \\
\hline nsur & 14.9372 \\
\hline intfw & 44.4333 \\
\hline irctrans & 6.73242 \\
\hline Izetp & 189.380 \\
\hline insur & $1.971448 \mathrm{E}-04$ \\
\hline retsc & 0.705840 \\
\hline \hline
\end{tabular}


matrix (i.e., the low sensitivity of the parameters NSUR (for the IMPLND application module), RETSC, and BASETP).

The comments that were provided above related to the eigenvalues and eigenvectors associated with the parameter covariance matrix strongly suggest that desired model complexity is too high relative to the information content of the data available to determine the model. This is highly noteworthy given that specified model complexity is low relative to a "typical" HSPF model application. The results from the PEST parameter estimation run also indicate that if one wants to include all of the desired model complexity to support simulation, then one must examine the impacts of parameter insensitivities and/or correlations on model predictions. That is, key model outcomes must be specified within the context of model predictive uncertainty.

As noted earlier in this document, PEST, using its predictive analysis mode, is capable of assessing the range of model predictions for key model outcomes, all the while keeping the model in a calibrated or almost calibrated state. In effect, the predictive analysis mode of PEST allows one to quantitatively examine the reliability of a "calibrated" model with respect to key desired model outcomes. Figure 7 presents PEST predictive analysis results, which were based on maintaining desired model complexity, for the annual summed flow for 1991-1993 at the location coincident with the streamflow-gaging station on Bautista Creek. PEST predictive analysis model runs were based on the arbitrary specification that the model was still assumed to be calibrated for objective function values 5 percent greater than the minimum objective function value obtained, using PEST's parameter estimation mode of analysis, for the HSPF model of Bautista Creek representative of current conditions. Examining Figure 7, the "calibrated" model predictive ranges for summed annual flow envelop the observed responses for 1991 and 1992 but not 1993. The results presented in Figure 7 suggest that perhaps more weight needed to be placed on the annual flows for the calibration period.

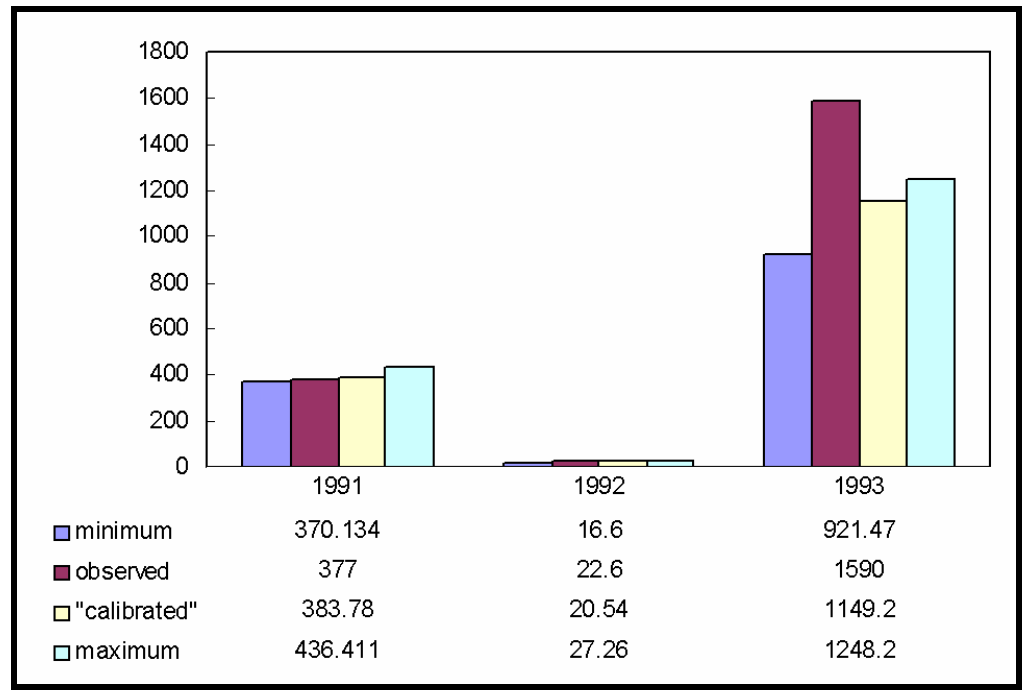

Figure 7. PEST predictive analysis results for total summed annual flows

Figure 8 presents PEST predictive analysis results, which were based on maintaining desired model complexity, for the total summed annual flow for 1991, for the "culturally unaltered," current, and future system conditions, at the location coincident with the streamflow-gaging station on Bautista Creek. Table 3 presents PEST predictive analysis results, which were based 
on maintaining desired model complexity, for the difference in total summed annual flow for 1991 between the current and "culturally unaltered" and the current and future system conditions, respectively. Examining the results presented in Figure 8 and Table 3, clearly, absolute model predictive uncertainties may be large while associated model predictive differences may be relatively small. PEST predictive analysis results for the "culturally unaltered," current, and future system conditions, based on maintaining desired model complexity, indicated that the model was unable to detect system change across the three system states. This was not surprising given the fact that there was very little system change across the three system states. Urban land constituted $0.00,0.27$, and 1.21 percent of the total land area above the streamflow-gaging station on Bautista Creek for the "culturally unaltered," current, and future system conditions, respectively. Model predictive uncertainty for the simplified HSPF model of Bautista Creek, representative of current conditions, could possibly be reduced by restructuring the model to eliminate and/or fix the parameters related to directly connected impervious cover and evapotranspiration loss by riparian vegetation. Doherty (2003) described a unique method to assess the hydrologic impacts of urbanization using PEST and HSPF.

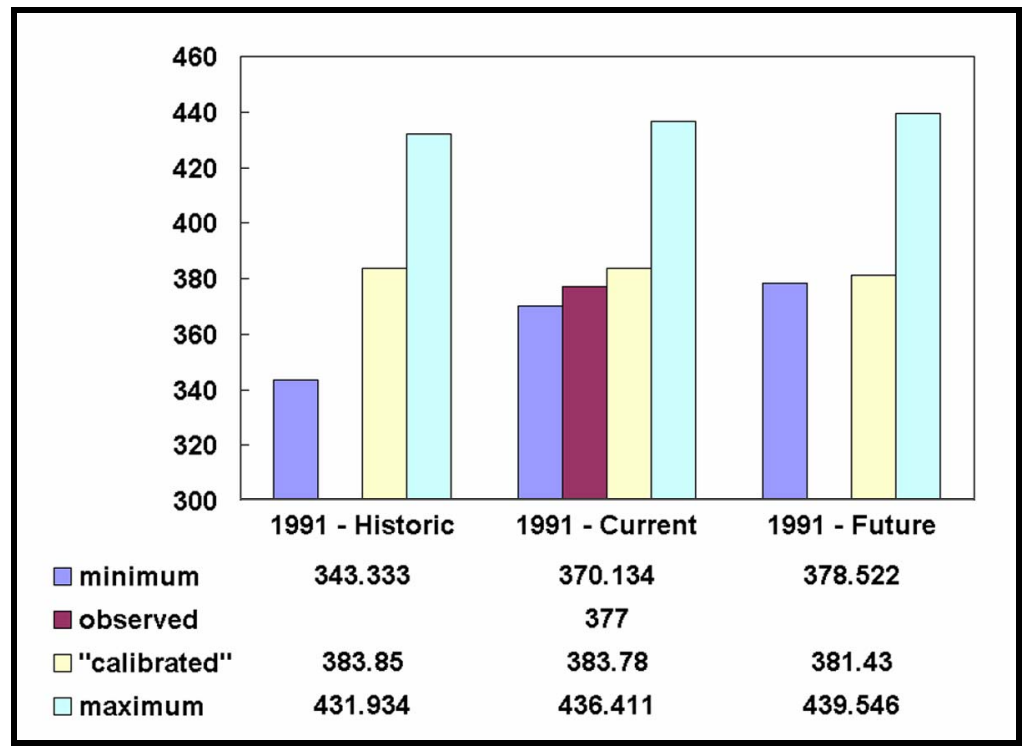

Figure 8. PEST predictive analysis results for total summed annual flow for current and historic system conditions

Table 3

PEST Predictive Analysis Results for Differences in 1991 Total Summed Annual Flow

\begin{tabular}{|l|l|l||}
\hline \hline Value & Current - “Culturally Unaltered” & Future - Current \\
\hline \hline Maximum & 0.38 & 2.61 \\
\hline Minimum & -1.13 & -5.42 \\
\hline
\end{tabular}

This case study application of Bautista Creek is rather unique in the spatial scales that were modeled using HSPF to meet the objectives of the supplementary studies. In contrast to a more representative or "typical" HSPF model application; for example, the study by Guay (2002), where the entire Bautista Creek system was treated as a single unit, 74 subwatersheds were modeled in Bautista Creek for the supplementary studies. Time requirements grow rather rapidly to develop and comprehensively evaluate an HSPF model as a system is further discretized (e.g., 
establish correct model topology, manage all of the time series data, and perform internal consistency checks). Fortunately, the WMS automatically determines a lumped model's topology during the development process. In contrast, spatially explicit outcomes are a natural by-product of the model development and application process for a distributed model. An obvious question that arises is when does one transition from using a lumped model, whose model structure was not originally designed to account for distributed watershed properties or to coherently treat the dynamics internal to a basin (e.g., an issue, related to spatial scale, that has arisen during the index level model assessment is the coarse way in which one can treat streamflow loss with HSPF), to a spatially explicit model, particularly when the management questions to be addressed by the simulation model are quite distributed in nature? For example, the index level model assessment objective of the supplementary studies for the San Jacinto and Santa Margarita SAMPs.

A separate technical document to be published at a later date will provide a comprehensive summary of the final results of the supplementary studies for the San Jacinto and Santa Margarita SAMPs.

SUMMARY: This report has provided a general description of the HSPF model, its capabilities and limitations, data requirements, traditional and innovative methods for HSPF hydrologic model calibration, and it has also presented a case study HSPF model application whereby the capabilities of HSPF and some of its ancillary public domain, off-the-shelf software are demonstrated as a means to support system-wide modeling and assessment in a usable decisionsupport framework.

The relatively unique case study application illustrated that modeling the hydrologic impacts of land use change and other anthropogenic influence is one context for which hydrologic simulation models can provide support to ecologically based assessment tools with indices all scaled to a reference condition (e.g., "culturally unaltered"). Despite more than 20 years of HSPF model application, there is no clear guidance information or tools available to support a credible HSPF model parameterization effort across various hydrologic response units (i.e., "land uses"). Clearly, there is a need for tools, and associated guidance information, that can support the credible extraction of HSPF model parameter differences across "land uses" using available data. Beven (2001) noted that assessing the hydrologic impacts of land use change is currently a rather popular indoor sport! It would be nice to do it correctly, if using HSPF. PEST was demonstrated to be a tool that can do just that while remaining within the bounds of historical/conventional HSPF model practice. Moreover, it can also subsequently look at how parameter uncertainty affects HSPF model uncertainty.

The results presented herein of the preliminary application of PEST to the HSPF model of Bautista Creek were promising in that PEST was able to assess model parameter sensitivities and correlations during the parameter estimation process. In addition, the predictive analysis mode of PEST was combined with the simplified HSPF model of Bautista Creek to evaluate scenario differences relative to model predictive uncertainty. While this specific application of PEST to the HSPF model of Bautista Creek may not be comprehensive relative to the overall objectives of the supplementary studies for the San Jacinto SAMP, it does provide the basis for quantification of the hydrologic impacts of urbanization on the riparian ecosystems. This 
PEST/HSPF application serves as a point of departure for more comprehensive HSPF model simulation support for assessing the impacts of the upland and also for further assessment of the index level model.

Planned future research and development activity at ERDC-Vicksburg in support of HSPF includes linking HSPF with the hydrodynamic water quality model CE-QUAL-W2, the preparation of guidance documents related to the appropriate use of PEST with HSPF within the context of TMDL and land use change analysis, and also linking PEST with HSPF in the WMS such that a robust PEST/HSPF linkage is widely accessible to the broad HSPF user community.

Numerous watershed scale hydrologic models are available today (Singh 1995), and new models are developed quite regularly. Oftentimes, for a given model study, it is not altogether clear which model to choose. There may be a handful that equally apply for the specified management objective they would support. One method for comparing alternate model structures, that could be viewed as an opportunity for future research, is utilization of the PEST tool that has been described in this document. If two models are equally applicable to a given management situation for which the modeling work will support, for an equivalent model misfit, what is the associated model predictive uncertainty for the key model outcomes? If the more complex modeling tool provides no less model predictive uncertainty for an equivalent model misfit, then this could possibly be viewed as solid justification for continued utilization of the simpler modeling tool.

POINTS OF CONTACT: This technical note was written by Dr. Brian E. Skahill s at the U.S. Army Engineer Research and Development Center, Vicksburg, MS. For additional information, contact Dr. Skahill (601-634-3441,Brian.E.Skahill@erdc.usace.army.mil) or the Manager of the System-wide Modeling Assessment and Restoration Technologies (SMART) Research Program, Dr. Steve Ashby, (601-634-2387, Steven.L.Ashby@erdc.usace.army.mil). This technical note should be cited as follows:

Skahill, B. E. (2004). "Use of the Hydrological Simulation Program - FORTRAN (HSPF) model for watershed studies," SMART Technical Notes Collection, ERDC/TN SMART-04-1, U.S. Army Engineer Research and Development Center, Vicksburg, MS.

\section{REFERENCES}

Bergman, M. J., and Donnangelo, L. J. (2000). "Simulation of freshwater discharges from ungaged areas to the Sebastion River, Florida," Journal of the American Water Resources Association 36(5), 1121-1132.

Beven, K. (1998). “Generalized Likelihood Uncertainty Estimation (GLUE),” Department of Environmental Science, Institute of Environmental and Natural Sciences, Lancaster University, Lancaster,UK.

Beven, K. (2001). Rainfall-Runoff Modelling, The Primer. John Wiley and Sons, Chichester.

Beven, K., and Binley, A. M. (1992). "The future of distributed models: Model calibration and uncertainty prediction." Hydrological Processes 6, 279-298.

Bicknell, B. R., Imhoff, J. C., Kittle, J. L., Jr., Donigian, A. S., Jr., and Johanson, R.C. (1996). "Hydrological Simulation Program - FORTRAN User's Manual for Release 11,' Environmental Research Laboratory, Office of Research and Development, U.S. Environmental Protection Agency, Athens, GA. 
Brigham Young University (1999). "Watershed modeling system reference manual.” Brigham Young University Environmental Modeling Research Laboratory, Provo, UT.

Crawford, N. H., and Linsley, R. K. (1966). "Digital simulation in hydrology: Stanford Watershed Model IV,” Technical Report 39, Department of Civil Engineering, Stanford University, CA.

Deliman, P. N., Pack, W. J., and Nelson, E. J. (1999). "Integration of the Hydrologic Simulation Program-FORTRAN (HSPF) Watershed Water Quality Model into the Watershed Modeling System (WMS)," Technical Report W-99-2, U.S. Army Engineer Research and Development Center, Water Quality Research Program, September.

Deliman, P. D., Ruiz, C. E., Donigian, A. S., Jobes, T. H., Nelson, E. J., and Manwaring, C. T. (2001). “Application of HSPF-AGCHEM Module within the WMS for the LeSueur Basin," Water Quality Technical Notes Collection (ERDC WQTN-MI-08), U.S. Army Engineer Research and Development Center, Vicksburg, MS.

Dinicola, R. S. (1990). "Characterization and simulation of rainfall-runoff relations for headwater basins in western King and Snohomish Counties, Washington," U.S. Geological Survey, Water Resources Investigations Report 89-4052.

Doherty, J. (2002). “PEST-ASP User’s Manual.” Watermark Numerical Computing. Brisbane, Australia.

Doherty, J., and Johnston, J. (2003). "Methodologies for calibration and predictive analysis of a watershed model," Journal of the American Water Resources Association 39(2), 251-265.

Donigian, A. S. (2002). "Watershed model calibration and validation: The HSPF experience." Water Environment Federation National TMDL Science and Policy 2002 Specialty Conference, November.

Donigian, A. S., Chinnaswamy, R. V., and Jobes, T. H. (1997). "Conceptual design of multipurpose detention facilities for flood protection and nonpoint source pollution control," AQUA TERRA Consultants, prepared for the Santa Clara Valley Water District.

Donigian, A. S., Jr., and Crawford, N. H. (1979). “User's Manual for Nonpoint Source (NPS) Model.” Unpublished Report. U.S. Environmental Research Laboratory, Athens, GA.

Donigian, A. S., Jr., and Davis, H. H. (1978). “User's Manual for Agricultural Runoff Management (ARM) Model.” EPA-600/3-78-080. U.S. Environmental Research Laboratory, Athens, GA.

Donigian, A. S., Jr., Bicknell, B. R., and Imhoff, J. C. (1995). "Hydrologic Simulation Program - FORTRAN.” Computer Models of Watershed Hydrology, Water Resources Publications, V. P. Sirgh, ed., Highlands Ranch, CO, 395-442.

Donigian, A. S., Jr., Imhoff, J. C., and Kittle, J. L., Jr. (1999). "HSPF-Parm: An interactive database of HSPF model parameters," Version 1.0, EPA-823-R-99-004.

Flynn, K., and Lumb, A. (1991). Computation and Modification of Meteorologic Time Series. Version 1.1. United States Geological Survey, Water Resources Division, Reston, VA.

Flynn, K. M., Hummel, P. R., Lumb, A. M., and Kittle, J. L., Jr. (1995). "User's Manual for Annie, Version 2, A Computer Program For Interactive Hydrologic Data Management." Water-Resources Investigations Report 95-4085, U.S. Geological Survey, Reston, VA.

Guay, J. R. (2002). "Rainfall.runoff characteristics and effects of increased urban density on streamflow and infltration in the eastern part of the San Jacinto River Basin, Riverside County, California," U.S. Geological Survey, WaterResources Investigations Report 02-4090, Sacramento, CA.

Hydrocomp, Inc. (1977). Hydrocomp water quality operations manual. Hydrocomp, Inc., Palo Alto, CA.

HydroGeoLogic, Inc., and AQUA TERRA Consultants. (1999). "Simulation Plan for Hydrologic Calibration of Tensas River Basin with Hydrologic Simulation Program - FORTRAN (HSPF)." Prepared for Robert F. Carousel, Work Assignment Manager, USEPA, Office of Research and Development, EPA Contract No. 68-C6-0020, June.

Johanson, R. C., Imhoff, J. C., and Davis, H. H. (1980). "User's Manual for the Hydrologic Simulation Program FORTRAN (HSPF).” EPA-600/9-80-105, U.S. EPA Environmental Research Laboratory, Athens, GA. 
Johnson, B. E., Skahill, B. E., Zhang, Z., and Samaitis, H. (2002). "Watershed water quantity and water quality modeling for Sinclair and Dyes Inlets," American Water Resources Association Spring Specialty Conference, May 13-15, 2002, New Orleans, LA.

Kittle, J. L., Jr., Lumb, A. M., Hummel, P. R., Duda, P. B., and Gray, M. H. (1998). "A tool for the generation and analysis of model simulation scenarios for watersheds (GenScn)." U.S. Geological Survey, Water-Resources Investigations Report 98-4134, Reston, VA.

Lichvar, R. 2000. Landscape Scale Delineation of Wetlands and Waters of the United States in the San Diego Creek Watershed Orange County, California. Final Report to the U. S. Army Corps of Engineers, Los Angeles District.

Lohani, V. K., Chanat, J., and Kibler, D. (2000). "Use of HSPF model in land use management in urbanizing watersheds," Virginia Tech. (http://landscapes.ce.vt.edu/publications/).

Lumb, A. M., McCammon, R. B., and Kittle, J. L., Jr. (1994). “User's manual for an expert system (HSPEXP) for calibration of the hydrological simulation program - FORTRAN." Water-Resources Investigations Report 94-4168, U.S. Geological Survey, Reston, VA.

Munson, A. D. (1998). "HSPF modeling of the Charles River Watershed," M.S. thesis, Department of Civil Engineering, Massachusetts Institute of Technology.

Nash, J. E., and Sutcliffe, J. V. (1970). "River flow forecasting through conceptual models. Part 1: A discussion of principles," Journal of Hydrology 10, 282-290.

National Research Council. (2001). "Assessing the TMDL approach to water quality management, Committee to Assess the Scientific Basis of the Total Maximum Daily Load Approach to Water Pollution Reduction," Water Science and Technology Board, National Academy Press, Washington, DC.

Northwest Hydraulic Consultants Inc., Mill Creek (Auburn) Hydrologic Modeling and Analysis. (1993a). Prepared for King County Division of Surface Water Management, City of Auburn, City of Kent.

Northwest Hydraulic Consultants Inc., Mill Creek (Auburn) HSPF Model Calibration. (1993b). Prepared for King County Division of Surface Water Management, City of Auburn, City of Kent.

Singh, V. P. (1995). Computer models of watershed hydrology. Water Resources Publications, V. P. Singh, ed., Highlands Ranch, CO.

Skahill, B. E. (2002). "A unified HSPF model to estimate loading from streams and storm water discharges into the receiving waters of Sinclair and Dyes Inlets," presentation at the PSNS Project ENVVEST Regulatory Working Group Meeting, June 20, 2002, Bremerton, WA.

Skahill, B. E., Johnson, B. E., and Deliman, P. N. (2002). “Application of GLUE to HSPF on Goodwin Creek," Second Federal Interagency Hydrologic Modeling Conference, July 28-August 1, 2002, Las Vegas, NV.

Skahill, B.E. (2003). "HSPF Modeling at the Engineer Research and Development Center," U.S. Army Corps of Engineers Watershed Systems 2003 Conference, May 13-15, 2003, Portland, OR.

Smith, R. D., Kleiss, B. A., Wakeley, J. S., Fischer, R. A., Johnson, B. E., Skahill, B. E., and Downer, C. W. (2002). "Scope of work for supplemental technical studies in the San Jacinto and Santa Margarita Watersheds in support of the Special Area Management Plan (SAMP)," U.S. Army Engineer Research and Development Center, Vicksburg, MS.

U.S. Army Corps of Engineers and U.S. Environmental Protection Agency. (2000). "HSPF/WMS Training Workshop." Vicksburg, MS, September 19-21.

U.S. Army Engineer District, Los Angeles. (2000). Draft Scope of Work, Special Area Management Plan, Santa Margarita and San Jacinto Watersheds, Riverside County, CA.

U.S. Army Engineer Research and Development Center (2002). "System-wide Modeling, Assessment, and Restoration Technologies (SMART) Program,” SMART Program Documentation, U.S. Army Corps of Engineers. 
U.S. Environmental Protection Agency. (1999a). "WDMUtil Version 1.0 (BETA) a tool for managing watershed modeling time-series data user's manual (DRAFT)." Exposure Assessment Branch Standards and Applied Science Division, Office of Science and Technology, Office of Water, Washington, DC.

U.S. Environmental Protection Agency. (1999b). "BASINS Technical Note 1, Creating hydraulic function tables (FTABLES) for reservoirs in BASINS," Office of Water, January.

U.S. Environmental Protection Agency. (2000a). "Bacterial indicator tool user's guide," Office of Water, EPA-823-B01-003, March.

U.S. Environmental Protection Agency. (2000b). "BASINS Technical Note 6, Estimating hydrology and hydraulic parameters for HSPF," Office of Water, July. (http://www.epa.gov/waterscience/ftp/basins/training/tutorial/TN6final.htm)

U.S. Environmental Protection Agency. (2001). “TMDL USLE Version 1.1," Center for Exposure and Assessment Modeling, National Exposure Research Laboratory - Ecosystems Research Division, Office of Research and Development, Athens, GA.

Whittemore, R. (2001). "Is the time right for consensus on model calibration guidance?" Editorial, Journal of Environmental Engineering, ACCE, 127(2), 95-96.

Whittemore, R. C., and Beebe, J. (2000). “EPA's BASINS Model: Good science or serendipitous modeling,” Journal of the American Water Resources Association 36(3), June 2000.

NOTE: The contents of this technical note are not to be used for advertising, publication, or promotional purposes. Citation of trade names does not constitute an official endorsement or approval of the use of such products. 